\title{
WAGE RIGIDITY, IMPLICIT CONTRACTS, UNEMPLOYMENT AND ECONOMIC EFFICIENCY
}

\section{David M. Newbery and Joseph E. Stiglitz}

The failure of standard competitive analysis to provide an adequate explanation of involuntary unemployment has provoked a variety of attempts to modify the theory so that it can account for such unemployment. Recent attempts fall into two main categories - efficiency wage models, in which the productivity of the firm's labour force depends on the wage it pays, and implicit contract theories. Both theories purport to explain wage rigidities. In the efficiency wage models, firms do not lower wages, even in the face of unemployment, because to do so lowers productivity. In the implicit contract theories, at least in the classical version (Baily, 1974; Azariadis, 1975), risk neutral firms provide some degree of insurance to risk averse workers against fluctuations in the worker's marginal productivity. Accordingly, wages will be less flexible than in the Walrasian model, and in extreme cases, will be rigid.

Though involuntary unemployment has often been attributed to wage rigidities, wage rigidities of the kind generated by implicit contracts by themselves may not be sufficient to generate unemployment. This paper is concerned with identifying the circumstances under which implicit contracts will give rise to unemployment. In particular, we investigate the implications of certain important features of implicit contracts (and of the economic environment in which firms operate) which have not been adequately recognised in earlier discussions. Implicit contract theory assumes that the workers and the firm sign a contract which maximises the expected profits of the firm, subject to the constraint that the expected utility of workers has to be at least high enough to be able to induce the worker to work for him. Insufficient attention, however, has been paid to (i) the general equilibrium consequences of these decisions; and (ii) the set of feasible contracts. Thus it has been incorrectly inferred that because each firm is maximising its profits, given the level of expected utility of workers, whatever equilibrium emerges with implicit contracts must be Pareto efficient.

This paper discusses a simple, general equilibrium model which explores three sources of restrictions on the set of feasible contracts: (i) Information: implicit contracts can only be written on the basis of information which is available or can be inferred by the workers and the firm; explicit contracts require, in addition, that any contingency provision be observable to an outside party. We thus distinguish between verifiability and observability. (ii) Enforcement: implicit contracts differ from explicit contracts in that there is no legal mechanism for enforcement. Two alternative mechanisms are available: reputation mechanisms, where bad behaviour of the firm is punished by increasing the cost of future recruitment, and self-enforcement mechanisms, 
where bad behaviour of the firm is punished by the withdrawal of effort of current workers. The analysis of these enforcement problems provides a critical link between efficiency wage and implicit contract theories: just as efficiency wage theory argued that lowering wages might lower profits by lowering workers' net productivity, we argue here more generally that abrogating the implicit contract may lower profits by increasing recruiting costs and reducing workers'. effort. (iii) Complexity: observed contracts have only a limited degree of complexity; they are usually not made contingent upon even the more important variables that economic theory suggests are relevant. We suspect that the problems of reaching an understanding about, and then enforcing, complex implicit contracts are even greater than those involved in explicit contracts.

We first show that in the absence of problems of observability, enforcement, and complexity, implicit contract theory, though explaining wage rigidity, will not give rise to unemployment. However, the market equilibrium is not constrained Pareto efficient.

The central objective of the paper is to see what happens when we drop one or more of these assumptions. We show that natural restrictions on enforceability alone or on the degree of complexity alone do not lead to unemployment, but that limited observability may lead to unemployment, though under conditions which do not seem very convincing. What does give rise to unemployment is the failure of two or more of these assumptions to be satisfied: in particular, restrictions on the complexity of a contract and its enforceability may lead to periodic unemployment.

\section{THE BASIC MODEL}

We present here a full general equilibrium model in which relative prices respond to shocks and are endogenously determined by market clearing conditions, yet is sufficiently simple that it can be solved explicitly. ${ }^{1}$ We consider a risk-neutral firm with a simple, fixed coefficients technology. ${ }^{2}$ So long as the capital constraint is not binding, the average and marginal productivity of a worker are the same. Suppose that the wage is rigid. The price must be sufficiently high not only to pay labour, but to obtain an adequate (expected) return on capital. If, when demand falls, the value of the marginal productivity of labour declines slightly, but still exceeds the wage then the lack of wage flexibility has no cost, but generates a clear benefit to the risk averse workers. If, on the other hand, the value of the marginal product declines enough, then with rigid wages there may be some induced unemployment. Given this trade-off between risk reduction and unemployment it seems plausible that the optimal contract will entail a sufficiently rigid wage that there is at least some probability of unemployment. The central question addressed in this paper is under what conditions this hypothesis is valid.

\footnotetext{
1 The model is set out in detail in Newbery and Stiglitz (1981, chapter 25), though we shall use it to derive a rather different set of results.

2 The fixed coefficient assumption is the easiest way of distinguishing between the long and the short run, and allowing for excess capacity - the counterpart to unemployment.
} 
We first formulate the general problem of the design of the implicit contract. There are two sectors in the economy, one of which produces an export crop using only labour. One unit of labour produces one unit of the export crop, which sells for a price $\tilde{p}$ in terms of the numeraire, which is the imported consumption good. Export price fluctuations are the source of risk: $\tilde{p}$ is a random variable. There is a second, non-traded, consumption good which is produced by means of a fixed coefficients technology:

$$
C=\min \left(N_{c} h, K / v\right),
$$

where $C$ is the output of the consumption goods industry, $N_{c}$ is employment in the industry, $h$ is the hours worked per worker, $K$ is the capital stock in the industry, and $v$ is the fixed capital-output ratio. Capital must earn an expected return of $r$.

Our concern is with the design of the optimal contract in the non-traded sector. Workers in the export sector are self-employed, and thus receive a wage of $\bar{p}$ (per unit of labour supplied). At the beginning of the period workers are freely mobile, but once they have decided whether to work in the export or non-traded goods sector, they are perfectly immobile.

This has the important consequence that layoffs result in unemployment, and captures the idea that in the short-run workers have industry-specific skills, and are thus vulnerable to industry-wide macro shocks. So long as there is less than perfect mobility, layoffs in one sector will cause some unemployment (see also footnote 2 on p. 417 ). All individuals are identical and have a standard utility function defined over their consumption of the imported consumption good (the numeraire), the non-traded consumption good, and leisure (work). It is convenient to represent this by the indirect utility function, $V=V(q, w)$, giving utility as a function of the wage received, $w$, and the price of the non-traded consumption good, $q$, provided that workers are not constrained in the amount of labour which they can supply. If they are constrained, then their utility can be represented by a modified indirect utility function $V=V(q, y, h)$, when their income is $y$, and the number of hours which they can work is $h$.

In equilibrium, there will be some relationship between the price of the export good (the exogenous source of uncertainty in this model) and the price of the non-traded consumption good, so that $q=q(\tilde{p} ; \boldsymbol{\Omega})$, where $\boldsymbol{\Omega}$ is a vector of market parameters, to be specified later.

Since for workers in the export sector (subscript $x$ )

$$
w_{x}=\tilde{p},
$$

the expected utility of workers in the export sector is

$$
W_{x} \equiv \mathrm{E} V[q(\tilde{p} ; \mathbf{\Omega}), \tilde{p}] .
$$

The equilibrium implicit contract in the non-traded consumption goods sector is 'agreed' before the state is known. How the contract is formulated depends on the assumptions concerning observability, enforceability, and complexity. 
I. I. Enforceable contracts with observability

First, we assume that any state contingent contract can be enforced. In Appendix I we prove the following two propositions:

Proposition I. If state contingent contracts are feasible and enforceable, the equilibrium (implicit or explicit) contract entails a specification of income and hours as a function of the state (i.e. functions $y(p)$ and $h(p))$ which entail full employment, in the sense that the individual's marginal rate of substitution between goods and leisure equals the marginal rate of transformation.

The explanation is the standard one that the wage contract should be viewed as the combination of a variable wage and an insurance contract which pays the difference between the agreed contract wage and the freely variable wage. Employment decisions are guided by the freely varying wage element, not by the more rigid contract wage.

Proposition 2. The contractual equilibrium is not, in general, constrained Pareto efficient. That is, there will exist some set of taxes and/or subsidies (on observable quantities) which would make everyone better off.

This theorem is another instance of the more general theorem that market equilibria with limited risk markets are not constrained Pareto efficient. In this case the inefficiency arises because of the public good nature of risk. Each firm, choosing its contract, takes the price distribution as given, but collectively these contract choices affect the price distribution and hence the nature of risk in the economy. As such, it is similar to the inefficiencies studied in Newbery and Stiglitz ( $1981 ; 1982 ; 1984)$.

\section{2. The enforcement problem}

The contracts described in the preceding section entailed the firm providing implicit insurance to the worker and so in bad states of nature, the payments to the worker exceed the value of his marginal product and provide an implicit subsidy. What is to stop the firm from reneging on the contract, for instance, by firing the worker? Conversely, in good states, the productivity of the worker exceeds his wage; what is to stop the worker from reneging on his contract, and going to work for another employer? If the workers' productivities are highly correlated at different firms, there will exist some firm willing to hire the worker at his marginal productivity. ${ }^{3}$ If contracts were explicit, and states of nature were observable and verifiable, (and individuals could sign contracts which bound them to their employers) then presumably the legal system could be employed to enforce the contracts. If firms hire individuals in good states, then the workers could pay the insurance premium in the initial year of employment, thus alleviating the problems associated with their reneging on the contract.

\footnotetext{
3 These are not the only enforcement problems. There is also a problem of ensuring that the worker does not shirk. In constructing models in which self-enforcement mechanisms are employed, one must be careful to note that if the worker has the power to reduce his effort when the firm breaches the (implicit) contract, the worker also has the power to reduce his effort if the firm does not breach. The perfect equilibria that one constructs must ensure that both sides comply. It is not difficult to construct such equilibria.
} 
But once the premium has been paid, what is to ensure that the firm honours its part of the contract?

The contractual arrangements between employers and employees, when explicit, seldom are long term; they seldom specify hours and employment; and even when they do, they are not, in general, contingent contracts (and even if they are, only a limited number of contingencies are specified, far short of the complete state contingency associated with the contracts of the preceding section). We need then a theory of implicit contracts.

There are two mechanisms by which implicit contracts can be enforced: reputations and what we shall refer to as self-enforcing mechanisms. Firms are concerned with how future employees view them; if they believe that they will not be well treated, they will only go to work for a firm if it pays them a sufficiently high wage to compensate for the mistreatment. Reputation as an enforcement mechanism may have limited efficacy if the interest rate is high and the firm is not planning to hire many individuals in the near future. In that case, the firm must resort to some self-enforcing mechanism, that is, its current workers must respond to a failure on the part of the firm to honour its part of the contract in a way costly to the firm.

For a contract to be enforceable, it is clear that breaches of the contract must be observable to outsiders (if the contract is being enforced through a reputation mechanism) or to insiders (the current workers). But employees clearly would not 'sign' a contract which the employer would have an incentive to breach. The contract is the best contract, subject to constraint that it is in the interests of both sides to carry out the terms of the contract. We are thus arguing that implicit contracts should be modelled as perfect equilibria of repeated games. In the following sections we discuss some simple models, showing that with limited observability and implicit contracts enforced by a self-enforcement mechanism, one can indeed obtain unemployment; while with less restrictive assumptions concerning observability, implicit contracts with full employment may emerge.

Even with explicit contracts there may be enforceability problems: it is costly to use the legal system, and thus, if the damages done by the breach of contract are small, it will not be employed. Moreover, to enforce contracts through the legal system requires a stronger condition than observability: it requires verifiability. Both sides to a contract may know (in their heart of hearts) that there has been a breach of contract but the fact of the breach must be established to a third, outside party, and this may be difficult to do. On the other hand, workers may insist on being paid a higher wage to go to work for a firm which has lost its reputation, or may reduce the effort they put out for the firm, even when the employer's breach of contract could not be enforced in a court of law. Thus, implicit contracts (contracts which have to be enforced through reputation and self-enforcement mechanisms) are not unambiguously 'weaker' than explicit contracts; they are, however, different.

Enforceability problems arise in conventional insurance contracts as well. Firms may default on their promises to pay; they may go bankrupt. The government has attempted to avoid these problems by imposing reserve requirements on insurance firms. No reserve requirement is imposed on firms 
for providing employment related insurance. (Indeed, it was only recently that reserve requirements were imposed on employee pension schemes in the United States.) Secondly, the terms of most insurance contracts are such that there is frequently ambiguity over whether a particular loss is covered, and if covered, the extent of coverage. Nor do contracts usually specify the speed with which claims are settled. Thus, there are important aspects of conventional insurance which are only enforceable by reputation.

If the state of nature were fully observable, a contract would specify the income and hours for the worker in a given state (which, in our model, is simply denoted by $p$ ). Under quite general conditions, we can model the enforceability problem in the following simple way. We postulate there to be a penalty associated with paying a wage different from the promised wage or of laying off a worker or making him work more than the agreed amount. The penalty associated with reneging on a contract ('losing one's reputation') is $J(p, \mathbf{\Omega})$, where $\boldsymbol{\Omega}$ is again a vector of market parameters. $J$ represents the reduction in the present discounted value of profits from a loss of reputation. (There is a close analogy here with the formulation used by Eaton and Gersovitz, $198 \mathrm{I}$, in their analysis of debt repudiation.) The firm considering laying off a worker that it has promised to pay a wage of $w(p)$, which exceeds the value of his marginal product, $q h$, has a one-time gain of $w-q h$. If the contract is to be enforceable by reputation, then

$$
w-q h \leqslant J(p, \Omega) \text { for all } p .
$$

The analysis of the market equilibrium is identical to that discussed in Appendix I (with the straightforward modification of the Lagrangian), and gives:

Proposirion 3. If there is complete observability and no restriction on the complexity of contracts, then there will be full employment, even if there are restrictions on the enforceability of contracts. These restrictions only limit the extent of the insurance provided by the firm.

The intuition behind this result is straightforward. Assume the firm employed a worker below his full employment level, so that the value of his marginal product exceeded his marginal rate of substitution (what he produced as a result of working an hour more exceeded what he needed to be compensated). Then, by asking the worker to work an hour more, profits could be increased: the incentive to abrogate the contract would be reduced. (And indeed, workers could be made better off at the same time.)

It will still be true that the market equilibrium will not be Pareto efficient, but now there is an additional source of inefficiency. The magnitude of the penalty will in general be a function of the wage, and the employment policies of all other firms. If that is the case, any single firm ignores its effect on the set of enforceable contracts, but the government, in deciding on the wage and employment policy, will take this effect into account.

\section{3. Restrictions on the complexity of contracts}

The contracts described in the previous two sections effectively require that wages (and hours worked) can be set as any function of the state of nature (the 
price of the export good, $p$ ). Provided the state is observable, then even if the contract can only be enforced by reputation, the optimal contract entails full employment. Wages may be partially rigid, but they are never so rigid as to give rise to unemployment.

Optimal contracts will equate the marginal utilities of income in all states, and the marginal rate of substitution to the marginal rate of transformation. Since in general the marginal utility of income and the marginal rate of substitution are complex functions of all prices, the optimal contract will in general specify wages and hours as a function of all prices, and the contingency contracts will differ among individuals. Moreover, to evaluate each contingency clause of the contract, the individual has to form probability judgements concerning the likelihood of the contingency.

In practice, it seems quite implausible that an implicit contract should be a very complex function of observable states, for even explicit contracts rarely take complex forms, if only because of the costs involved in either agreeing the contract, or verifying the relevant state sufficiently accurately. Since an implicit contract is by definition implicit, only simple forms will be feasible if it is to be possible to detect breaches of the contract. The question is whether natural restrictions on the degree of complexity of the contract result in unemployment. In the model the source of the disturbance is the variability in the export price, $p$, which affects income, demands, the price of the non-traded good, $q$, and hence the value of the marginal product of labour. Since both the firm and the worker are more concerned with the level of $q$ than $p$, it would be preferable to make the wages some function of $q$ (i.e. to be partially indexed on the product price). If the price were publicly observable and non-manipulable this would be possible (and there are examples in Victorian England of mine wages being indexed to the price of coal). Most non-traded goods and services are sold in imperfectly competitive markets, in which the prices may be hard to observe, as they will be subject to discounting, price discrimination, and the like. In bad states of the world the firm will have an incentive to claim that extensive discounting was necessary to maintain sales, but it might be hard to verify the prices actually charged. (Oswald, I986, makes essentially the same argument in ruling out the possibility of indexing on the product price.) We shall therefore assume that it is impossible to index on $q$, in which case the natural choice is to index on $p$ (which is effectively the exchange rate in this model). We shall assume that the set of contracts is restricted to those in which wages are a linear function of the export price $p(s)$ in state $s$ :

$$
\frac{w(s)-\bar{w}}{\bar{w}}=(\mathrm{I}-\rho) \frac{p(s)-\bar{p}}{p} \quad(0 \leqslant \rho \leqslant \mathrm{I}) .
$$

Here mean values are denoted by a bar, $w(s)$ is the wage in the non-traded (or urban) sector when the export price is $p(s)$, and $\rho$ measures the degree of wage rigidity. If $\rho=0$ then urban wages are identical to agricultural wages (from (2)) and utility levels will automatically be equated, as required by (3). If $\rho=\mathrm{I}$, urban wages are perfectly rigid and equal to $\bar{w}$, and the level of $\bar{w}$ will be determined by equation (3).

It is possible to think of alternative simple wage contracts which in specific 
cases may be superior to the linear case considered here - one natural choice would be to make the money wage constant unless $p$ fell below some critical level $p^{*}$, after which it might be proportional to $p$ (or some linear function of $p$, as in (5)). This would have the advantage that the wage would only be cut in states in which the alternative were layoffs, but it would have two obvious draw-backs. The first is that it would rather perversely lead to lower real wages in good states, when labour demand and consumer prices are high. The second is that it is likely to prove more difficult to reach agreement on a choice of $p^{*}$, than on the parameters of the flexible linear contract, (5), since it will require more information about the probability distribution of $p$ and the causal links between $p$ and $q$. (It requires far less data to estimate the mean of a series than its variance.) Whilst it is interesting to speculate on what constitutes a 'simple' contract, this is somewhat tangential to our main point. Our argument is that if the complexity of the wage contract (number of parameters) is significantly less than the complexity of the risk (dimension of the state space) - as we would argue it almost always is - then unemployment will be observed in bad states even with the best feasible contract, if contracts are not enforceable except by reputation. Two other points seem worth making. The first is methodological. In any model it is necessary to simplify drastically in the interests of tractability and transparency. In such a model it may well be that a well-chosen formula for the wage contract with a small number of parameters will achieve (almost) ideal risk sharing with no layoffs. But this would be a consequence of the simplicity of the model, and a misleading conclusion to draw in general. The second is that most contracts are much simpler than those considered here, since it is rare for contracts to be explicitly indexed on any firm- or industry-specific measure of productivity.

In the same spirit, the contract might make the number of hours worked, $h$, a linear function of the export price, $p$. Rather than model the particular form unemployment takes (work sharing or layoffs) we shall assume that there is perfect work sharing, so individual hours worked vary directly with aggregate labour demand. All workers are identical and have the (constrained) indirect utility function

$$
V(q, y, y)=\log (2-h)+\log y-\beta \log q .
$$

In the absence of lump sum transfers, income $y=w h$, and if labour supply is unconstrained, workers will always choose $h=\mathrm{I}$, so that full employment is easily defined. Clearly the optimal simple contract will also specify $h=\mathrm{I}$.

Again, with full observability and enforceability, the contract will be equivalent to a freely variable wage element, $w^{*}(s)$, and an insurance payment, $w(s)-w^{*}(s)$, where $w^{*}(s)$ is the marginal product of labour in state $s$, and $w(s)$ is given by equation (5). Employment decisions are governed by $w^{*}(s)$, and will therefore be set at full employment with no layoffs, whilst the limits on complexity will only affect (to a minor degree) the extent and nature of risk sharing. Restricting the complexity of contracts by itself does not seem to explain the existence of periodic unemployment.

Notice, however, how our choice of utility functions has biased our result. If we had chosen a utility function for which optimal $h$ increased with $q(p)$, then 
there would have been a conflict: a contract that specified $h$ would have entailed underemployment in some (good) states, overemployment in others; a contract that left $h$ to the discretion of firms would have lead to employment variability, but with variable wages there would be underemployment in bad states, overemployment in good. In general, simple formulas, e.g. making $h$ a linear function of $p$ would ameliorate but not eliminate these problems.

\section{4. Limited Observability}

So far, we have assumed that the state of nature is perfectly observable to both firms and workers. Assume, however, that the state of nature is observable to the firm, but not to the worker. If, for instance, workers had a separable utility function of the form $U(c)-V(h)$, then the first best insurance contract would have $y(p)=y^{*}$, independent of $p$, but $h$ larger in states where $p$ is higher (where $q$, the price of output, and hence the marginal value of output, is higher). The worker could not, in these circumstances, trust the firm to tell the truth about which state of nature prevails because the firm would always announce that it is the state with the highest $p$. Contracts can now take on one of two forms: (i) pooling contracts, in which the terms of the contract are not state contingent; and (ii) separating contracts, in which they are. To induce firms to tell honestly what state it is, the set of (hours, wages) among which the firm must select must be restricted in some way. The nature of the restriction - and in particular, whether the restriction entails underemployment in some states-depends critically on a number of assumptions. The standard assumption in the self-selection literature (Azariadis and Stiglitz, I983; Hart, 1983) is that although workers cannot observe the state of nature, they know the firms' technology and the probability distribution of the states of nature. This allows them to ascertain whether a particular set of (hours, wages) choices is consistent with self-selection, and allows them to evaluate their expected utility associated with the contract choice. The standard theory of self-selection then gives

Proposition 4. With one period explicit contracts, there is never a complete pooling equilibrium; there is either underemployment in the bad states, or overemployment in the good states, provided that the 'single crossing property' holds (that is, the marginal product of labour is higher in good states for all employment levels).

There are several characterisation theorems in the literature specifying conditions under which under- or over-employment result, showing this to depend on the worker's utility function and the degree of risk aversion of firms. (With a separable utility function, and risk neutral firms, there is always over-employment.) Utility functions of the form $U[y-\phi(h)]$ and risk neutral firms give full employment, but if the firm is sufficiently risk averse, there will be under-employment. With a third party providing insurance to risk averse firms, one always obtains under-employment. (See Grossman and Hart, I981 ; 1983; Hart, 1983; Azariadis and Stiglitz, 1983; and Stiglitz, 1984.)

On the other hand, if there are a large number of periods, a sufficiently low interest rate, and a sufficiently low correlation of good and bad states, then truthtelling can be enforced by imposing restrictions on the probability 
distribution of announcements. If there are only two states, each occurring with probability 0.5 , we can say, for instance, that within the first $T$ periods, the ratio of good to bad states announced must lie within a certain interval. Indeed, it is possible to establish $:^{4}$

Proposition 5. If the two states of nature are independent and equally probable, and if the interest rate is low enough, then there exists a sufficiently long contract of length $T$, which requires that the firm announce that it is state I not less than $0.5-\epsilon$ of the time and not more than $0 \cdot 5+\epsilon$ of the time, and which comes arbitrarily close to the contract which would have been chosen with full observability.

The informational requirements associated with these contracts are much less than those associated with the one period self-selection contracts. There, workers had to know the technology in order to ensure that the contracts satisfied the self-selection constraints; and in order to evaluate the contracts, they had to know the probability distribution of the two states. Here, we only require that the firm announce the two contracts and the fraction of the time that it will use each contract. The worker can evaluate this contract directly and it will be in the interests of the firm to design an efficient contract.

Reality may not be well described by either Proposition 4 or Proposition 5 : cortracts extend for more than one period, but not for arbitrarily long durations. Optimal multi-period contracts are very complicated: they require that the choice set made available to the firm at date $t$ be made contingent upon the entire history of announcements up to that date.

\section{MULTIPLE CONTRACT RESTRICTIONS}

In the previous section we argued that restrictions on the observability of states of nature, of enforceability of the contract, or on the complexity of the contract do not in general lead to unemployment if only one restriction is imposed on

We omit the mathematical details here and just sketch the intuition and proof. Assume we could somehow enforce a stipulation that half of the time the firm must announce that it is the good state 1 , assume the interest rate is zero, so that the criterion becomes one of maximising the average value of profit, subject to the average value of utility. The firm must specify $\left(h_{j}, y_{j}\right)(j=1,2)$ and the fraction of the time it will lie about the state it is in, $\delta$. The Lagrangian is

$$
\begin{aligned}
L= & (1-\delta) \sum_{j=1}^{2}\left\{\left(h_{j} q_{j}-y_{j}-r K\right)+\lambda\left[V\left(q_{j}, y_{j}, h_{j}\right)-W_{x}\right]\right\} \\
& +\delta \sum_{j=1}^{2}\left\{\left(h_{j} q_{i}-y_{j}-r K\right)+\lambda\left[V\left(q_{i}, y_{j}, h_{j}\right)-W_{x}\right]\right\} \quad(i \neq j) .
\end{aligned}
$$

The analysis follows that in Appendix I exactly if $\delta=0-$ i.e. if it pays the firm to tell the truth. The condition for this to be desirable is very weak - for if it lies by announcing it is a bad state when in fact it is good, then it will have to pay the good contract in some state when in fact it is bad, and this will typically be more costly then the earlier gain. As before, the result is full employment. For large enough $T$, the probability that the fraction of dates at which the state has been good lies in $(0.5-\epsilon, 0.5+\epsilon)$ can be made arbitrarily close to I. An inefficiency occurs in these small probability cases; for the firm will be required to announce that it is state 1 when it is in fact state 2 (or conversely), though only (usually) a small fraction of the time. The loss from such mislabelling is bounded, and since the frequency with which these losses occurs goes to zero, the total value of these losses (normalised, e.g. per period) goes to zero. The restriction on the rate of interest being small is required because at sufficiently high interest rates, the gains from saying, for instance, that it is state 2, when it is state 1 , exceed the present discounted value of the losses (which occur later) which occur when the firm is forced to say that it is state $I$, when it is in fact state 2 . 
the standard model. In this section we shall argue that two or more of these restrictions will in general give rise to intermittent unemployment, and we demonstrate this for the case of simple implicit contracts, where the contract must be enforced by reputation, and the wage paid in a linear function of the export price, $p$, given by equation ( 5 ).

There are two possibilities. In the first case the contract specifies only wages and not hours, whilst in the second case it specifies both wages and hours as a function of $p$. In the first case the firm is free to choose the number of hours (level of output) and in equilibrium firms will choose employment so that they never make a loss on variable costs. In this case the contract is self-enforcing and reputation is not necessary. It is relatively straightforward (though too space consuming to present here) to show that the optimal linear wage contract can lead to unemployment in sufficiently adverse states. The details and numerical examples are presented in Newbery and Stiglitz (1985). The firm must choose the degree of rigidity, $\rho$, and the average wage, $\bar{w}$, to minimise the average labour cost of production whilst ensuring workers a high enough expected utility to be willing to work for the firm. As the degree of rigidity is changed, and the wage rate adjusted, the cost of producing the non-traded good will change, and so will its market clearing price. This in turn affects the welfare of workers, and these general equilibrium effects need to be traced through in determining the optimal contract.

The optimal contract balances off unemployment and risk sharing. If wages are very flexible, there will be fewer states in which unemployment will occur; but workers lose utility from the variability in wages. With more wage smoothing, there is less risk bearing if the state is not too bad, but unemployment if it is. Indeed, this insight is at the heart of the original discussions of implicit contracts: the problem has been to find the setting under which it is valid.

For unemployment to occur with the optimal contract there must be more states of the world than the number of parameters used to describe the wage contract, for otherwise the contract can essentially mimic a state-dependant contract, which we have shown avoids the problem of layoffs. This explains why in Newbery and Stiglitz ( $198 \mathrm{i}$, p. 387) it was never desirable to choose a degree of wage rigidity which caused unemployment, for the numerical example presented there had only two states of the world, good and bad. With four states, however, the model remains sufficiently simple to solve and is capable of generating unemployment. The numerical results presented in Newbery and Stiglitz ( 1985 , Table I) accord with intuition, and confirm the following. As the risk of adverse states of the world falls (i.e. as the probablity of the lowest of the four possible export prices falls) so the optimum degree of wage rigidity rises and unemployment rises (though the average level of unemployment may rise and then fall). As the variability of the export price increases, so does the optimum level of unemployment in the adverse state. As the share of wages in average value-added rises, so does the optimum level of unemployment in the adverse state, as the more likely it is that unemployment will occur for any given level of wage rigidity. Finally, the smaller is the share of the non-traded good in the workers' consumption bundle, the smaller will be the fluctuations in the 
cost of living, and the higher will be the optimum level of unemployment in adverse states, as greater nominal wage rigidity will be more desirable.

In the second case where hours can be made a function of $p$, the analysis of equilibrium is more complex. If demand is sufficiently low, the market clearing price at full employment output and agreed wages may be so low that firms are experiencing high current losses, and thus have an incentive to renege on the contract. This can be limited by the consequent loss of reputation, but if the firm's discount rate is high enough, the contract will be broken in sufficiently adverse states.

The equilibrium in these states will be one in which a fraction of firms close down (declare bankruptcy), and thus, by reducing output, prevent the price falling too far. At the equilibrium price, firms remaining in business make current losses sufficiently large that they are indifferent between operating, and retaining their reputation, or closing down, avoiding the loss, but losing their reputation. The value of reputation is equal to the difference in present discounted value of paying workers their marginal product state by state (i.e. offering no insurance), and paying them according to equation (5). Since the insurance is valuable, it is cheaper to obtain workers when wages are smoothed.

Similar results obtain even if contracts can be made contingent upon $q$, so long as the firm's product price is not observable without error and so long as other firms' prices are not perfectly correlated with the firm's price. (The incentives for firms to misrepresent their prices are obvious - if $w$ is lowered when $q$ is lowered, firms will attempt to report a lower than true value for $q.)^{5}$ The frequently observed problems of firms attempting to (and in some cases succeeding in) renegotiating the wage in the face of a decline in the demand for a firm's products (or an increase in the costs of other inputs) indicates the absence of sufficiently flexible indexing of explicit contracts, and is suggestive of the similar problems in implicit contracts.

\section{CONGLUSIONS}

There are no simple explanations of involuntary unemployment. Earlier Keynesian models, and the subsequent fixed price literature, made a contribution in identifying the importance of wage rigidities for unemployment. Wage rigidities, however, are not sufficient by themselves to generate unemployment. Standard implicit contract theory provided an explanation of wage rigidities, but it did not explain unemployment. This paper has asked whether certain natural restrictions on the set of feasible contracts will lead to unemployment. We have shown how plausible versions of the restrictions implied by limitations on information, enforcement, and complexity, taken one at a time, do not lead to unemployment. But in fact, all of these limitations are present at the same time. Under these circumstances, implicit contracts can then provide an explanation of unemployment.

B If other firms' $q$ is imperfectly correlated then as before the optimal contract dependant on, say $\bar{q}$ (the average of other firms' $q$ ) and $p$ in which firms are given discretion over $h$ will entail unemployment, and if the conditional variance is high enough, some firms will renege in bad states on contracts in which hours are made functions of $\bar{q}$ and $p$. 
We have emphasised the insurance role of implicit contracts. There is another set of explanations for the long term relationships between workers and firms, based on transactions costs. Though formally modelling the implications of transactions costs for contract design is no easy matter, it seems plausible that such considerations reinforce the importance which we have attributed to the limitations of contract complexity.

\section{Churchill College, Cambridge}

Princeton University

Date of receipt of final typescript: November 1986

\section{REFERENCES}

Akerlof, G. and Miyazaki, H. (I980). 'The implicit contract theory of unemployment meets the wage bill argument.' Review of Economic Studies, vol. 47 (2), pp. $321-38$.

Azariadis, C. (1975). 'Implicit contracts and under-employment equilibria.' Journal of Political Economy, vol. 83 , pp. I $83-202$.

- and Stiglitz, J. E. ( 1983$)$. 'Implicit contracts and fixed price equilibria'. Quarterly Journal of Economics, vol. 98 , Supplement, pp. I-22.

Baily, M. A. (1974). 'Wages and employment under uncertain demands.' Review of Economic Studies, vol. 4I, pp. $37-5^{\circ}$.

Eaton, J. and Gersovitz, M. (1981). 'Debt with potential repudiation: theoretical and empirical analysis.' Review of Economic Studies, vol. 48, no. 152, pp. 289-309.

Grossman, S. and Hart, O. ( $198 \mathrm{r}$ ). 'Implicit contracts, moral hazard, and unemployment.' American Economic Review (papers and proceedings), vol. $71 . \mathrm{pp} .3^{\circ} \mathrm{I}-7$.

— - (1983). 'Implicit contracts under asymmetric information.' Quarlerly Joumal of Economics, vol. 98. pp. $1223-56$.

Hart, O. (1983). 'Optimal labour contracts under asymmetric information: an introduction.' Review of Economic Studies, vol. 5o. pp. 3-36.

Newbery, D. M. G. and Stiglitz, J. E. ( 1981 ). The Theory of Commodity Price Stabilization. Oxford University Press.

- and- $(1982)$. 'The choice of techniques and the optimality of market equilibrium with rational expectations.' Journal of Political Economy, vol. go (2), pp. 223-46.

- and - ( 1984 ). 'Pareto inferior trade.' Review of Economic Studies, vol. 51, pp. I-12.

and- ( 1985$)$. 'Wage rigidity, implicit contracts, unemployment and economic efficiency.' CEPR Discussion Paper no. 67. Centre for Economic Policy Research, London.

Oswald, A. J. (1986). 'Unemployment insurance and labor contracts under asymmetric information: theory and facts'. American Economic Review, vol. 76, June, pp. 365-78.

Stiglitz, J. E. (1984). 'Theories of wage rigidity,' NBER Working Paper, no. I 442.

\section{APPENDIX I. PROOF OF PROPOSITIONS I- 3}

The contract will be chosen to maximise profits, subject to two constraints; $(i)$ it must be possible for the firm to hire workers, i.e., the expected utility of workers under the contract must be at least $W_{x}$; and (ii) the contract must satisfy the enforceability constraints discussed in the text. In equilibrium the number of firms in the industry will be such that (the maximised value of expected net) profits in the industry are driven to zero. For purposes of comparison with the constrained social optimum, it is more convenient if we analyse the dual of the problem that we have just formulated; i.e., consider the contract which maximises the expected utility of workers, subject to a constraint on profits (which, in equilibrium, is simply the zero net profit constraint), and subject to the enforceability constraint. Thus, the implicit contract maximises

subject to

$$
\mathrm{E} V[q(p ; \mathbf{\Omega}), y(p), h(p)]
$$

$$
y(p)-h(p) q(p ; \mathbf{\Omega}) \leqslant J(p ; \mathbf{\Omega})
$$




$$
\begin{gathered}
K / v \geqslant N_{c} h(p) . \\
\mathrm{E}[h(p) q(p ; \boldsymbol{\Omega})-y(p)] \geqslant r K / N_{c} .
\end{gathered}
$$

The first is the enforceability constraint (with $J=o$ for Proposition I), the second is the production efficiency condition of equation ( 1 ), and the last is the zero profit constraint. The definition of a competitive rational expectations equilibrium is standard - firms take as given the relationship between the market price $q$ and the state $p$, which is determined by the market clearing conditions for $q$. (See e.g. Newbery and Stiglitz, 1982). Their optimal choices reproduce this relationship, and labour allocates itself between sectors to equate ex ante expected utility.

Propositions 1 and 3 . An equilibrium implicit contract with or without the enforceability constraint entails full employment. ${ }^{6}$

Proof. The maximisation problem (A I)-(A 4 ) can be written as a Lagrangian to be maximised:

$$
\begin{aligned}
L= & \mathrm{E}\{V[q(p), y(p), h(p)]+\lambda(p)[J(p ; \mathbf{\Omega})+h(p) q(p)-y(p)] \\
& \left.+\nu(p)\left[K / v-N_{c} h(p)\right]+\mu\left[h(p) q(p)-y(p)-r K / N_{c}\right]\right\},
\end{aligned}
$$

where the expectation operator applies to all terms, and the vector of market parameters, $\mathbf{\Omega}$, has been omitted for brevity. The market equilibrium contract must satisfy the first order conditions (differentiating with respect to $y$ and $h$ in each state, p),

$$
\begin{gathered}
V_{y}-\lambda(p)-\mu=0, \\
V_{h}+q(p)[\lambda(p)+\mu]-v(p) N_{c}=0 .
\end{gathered}
$$

Dividing (A 7) by (A 6) gives

$$
\frac{V_{h}}{V_{y}}=-q\left(\frac{\lambda+\mu-\nu N_{c} / q}{\lambda+\mu}\right)
$$

Hence, if $\nu=0$, i.e. capital is not fully utilised ( $h$ is less than $\left.h_{\max }\right): V_{h} / V_{y}=-q$. The marginal rate of substitution between leisure and consumption goods must equal the value of the marginal productivity of labour: the implicit contract entails full employment as defined even when the enforceability constraint is binding. (When $\nu>0$, i.e. capital is fully employed, then $h$ is given by $h=h_{\max }=K / v N_{c}$. The marginal product of labour is not well defined; it is zero for increases in labour, $q$ for decreases in labour. Equation (A 8) says that the marginal rate of substitution is greater than zero but less than $q$.)

Propositron 2. An implicit contract equilibrium is in general constrained Pareto inefficient unless agents are risk neutral.

Proof. (Sketch - for details see Newbery and Stiglitz, i985). Consider the optimal policy of a government which controls the non-traded goods sector, but which faces the same enforceability constraints as does the private sector, and which can only affect the sectoral allocation of labour by non-state dependent but sector-specific lump sum taxes or subsidies, $t$. The government's problem can be summarised by the Lagrangian

$$
\begin{aligned}
L= & \mathrm{E}\left[N_{c} V(q, y+t, h)+\alpha\left(N-N_{c}\right) V^{x}\left(q, p,-\frac{t N_{c}}{N-N_{c}}\right)+\lambda(p)[J(p, \mathbf{\Omega})+h q-y]\right. \\
& \left.+\nu(p)\left(K / v-N_{c} h\right)+\mu\left(h q-y-r K / N_{c}\right)+\xi N_{c}\left(V-V^{x}\right)\right],
\end{aligned}
$$

where the control variables are $\left(y, h, t, N_{c}, K\right), q$ is a function of the control variables

- This result parallels that of Akerlof and Miyazaki (1980), but they did not allow workers to vary the number of hours that they worked, nor did they impose the enforceability constraint. 
given by the market clearing condition, and where superscript $x$ refers to the export sector. Suppose that initially $\partial J / \partial q=0$. Differentiate (A g) to obtain

$$
\begin{gathered}
\frac{\partial L}{\partial y}=N_{c}(\mathrm{I}+\xi) V_{y}-(\lambda+\mu)+\frac{\partial L}{\partial q} \frac{\mathrm{d} q}{\mathrm{~d} y}=0, \\
\frac{\partial L}{\partial h}=N_{c}(\mathrm{I}+\xi) V_{h}+q(\lambda+\mu)-\nu N_{c}+\frac{\partial L}{\partial q} \frac{\mathrm{d} q}{\mathrm{~d} h}=0 .
\end{gathered}
$$

The competitive market will be efficient if there exists a value of $\alpha$ for which (A Io) and (A I I) are consistent with (A 6 ) and (A 7) when $t=0$. If $\partial L / \partial q=0$, then the two solutions coincide, but in general $\partial L / \partial q \neq 0$ and hence the market equilibrium will be inefficient.

It is fairly straightforward to examine the conditions needed for $\partial L / \partial q=0$ and to show that they are essentially the same as those established by Newbery and Stiglitz ( 1982 ), namely that risk markets must be redundant. (See Newbery and Stiglitz, 1985 , Appendix I). If $\partial J / \partial q \neq 0$, the conditions for the market equilibrium to be constrained Pareto efficient will be even more restrictive. 
Copyright of Economic Journal is the property of Blackwell Publishing Limited. The copyright in an individual article may be maintained by the author in certain cases. Content may not be copied or emailed to multiple sites or posted to a listserv without the copyright holder's express written permission. However, users may print, download, or email articles for individual use. 